\title{
Primary neurons that express the L2/HNK-1 carbohydrate during early
}

\section{development in the zebrafish}

\author{
WALTER K. METCALFE, PAUL Z. MYERS*, BILL TREVARROW $\dagger$, MICHAEL B. BASS $\ddagger$ and \\ CHARLES B. KIMMEL
}

Institute of Neuroscience, University of Oregon, Eugene, OR 97403, USA

Present addresses:

* Department of Biology, University of Utah, Salt Lake City, Utah 84112, USA

$\dagger$ Division of Biology, California Institute of Technology, Pasadena, CA 91125, USA

¥Battelle, Pacific Northwest Labs, Box 999, Richland, WA 99352, USA

\section{Summary}

In zebrafish, many nerve pathways in both the CNS and periphery are pioneered by a small and relatively simple set of 'primary' neurons that arise in the early embryo. We now have used monoclonal antibodies to show that, as they develop, primary neurons of several functional classes express on their surfaces the L2/HNK-1 tetrasaccharide that is associated with a variety of cell surface adhesion molecules. We have studied the early labeling patterns of these neurons, as well as some non-neural cells, and found that the time of onset and intensity of immunolabeling vary specifically according to cell type.

The first neuronal expression is by Rohon-Beard and trigeminal ganglion neurons, both of which are primary sensory neurons that mediate touch sensitivity. These cells express the epitope very strongly on their growth cones and axons, permitting study of their development unobscured by labeling in other cells. Both types initiate axogenesis at the same early time, and appear to be the first neurons in the embryo to do so. Their peripheral neurites display similar branching patterns and have similar distinctive growth cone morphologies. Their central axons grow at the same rate along the same longitudinal fiber pathway, but in opposite directions, and where they meet they appear to fasciculate with one another. The similarities suggest that Rohon-Beard and trigeminal ganglion neurons, despite their different positions, share a common program of early development.

Immunolabeling is also specifically present on a region of the brain surface where the newly arriving trigeminal sensory axons will enter the brain. Further, the trigeminal expression of the antigen persists in growth cones during the time that they contact an individually identified central target neuron, the Mauthner cell, which also expresses the epitope. These findings provide descriptive evidence for possible roles of L2/HNK-1 immunoreactive molecules in axonal growth and synaptogenesis.

Key words: adhesion, guidance, Mauthner, Rohon-Beard, trigeminal, Golgi, HNK-1.

\section{Introduction}

How do developing neurons acquire their specific morphologies, grow their axons along specific pathways and recognize specific target cells? Evidence is accumulating that interactions that specify cell type (Knust and Campos-Ortega, 1989), as well as axonal guidance (Dodd and Jessell, 1988), are mediated by molecules present on the cell surface. For example, molecules involved in guidance include the fasciclins (Harrelson and Goodman, 1988), neural-cell adhesion molecule (N-CAM; Rutishauser and Jessell, 1988), and L1 (Moos et al. 1988).

In previous reports, it has been shown that a cellsurface carbohydrate moiety, termed the L2/HNK-1 tetrasaccharide, is present in the neural cell adhesion molecules L1 and N-CAM (Kruse et al. 1984), myelinassociated glycoprotein (MAG; McGarry et al. 1983), and the $\mathrm{J} 1$ glycoprotein (Kruse et al. 1985). Further, the L2/HNK-1 tetrasaccharide may itself be involved directly as a ligand in cell interactions (Künemund et al. 1988; Keilhauer et al. 1985; Riopelle et al. 1986). For example, perturbation experiments have shown that the L2/HNK-1 tetrasaccharide mediates interactions between the neuronal cell surface and a variety of substrates in vitro (Künemund et al. 1988). In addition, L2/HNK-1 has been shown to be present on the surface of migrating neural crest cells in avian embryos (Vincent et al. 1983), and in vivo application of the HNK-1 antibody, which binds the L2/HNK-1 antigen, disrupts 
normal neural crest cell migration (Bronner-Fraser, 1987). Thus, the L2/HNK-1 epitope may be important in the organization of the vertebrate nervous system, either by itself, or by its association with cell adhesion molecules.

Here we characterize the temporal and spatial patterns of expression of the L2/HNK-1 tetrasaccharide in zebrafish embryos, focusing in particular on primary neurons. We wanted to determine whether its in situ pattern of expression provides clues as to the functional role of this tetrasaccharide, or of the molecules with which it is associated. Primary neurons are a distinct set of large neurons that arise early, rapidly develop long axons and interconnect to form a simple neural network that mediates the early behaviors of the embryo (Herrick and Coghill, 1915; Grunwald et al. 1988; Kimmel and Westerfield, 1990). Primary neurons also pioneer neural pathways followed by large numbers of other neurons developing at later times (Kimmel and Westerfield, 1990; Wilson et al. 1990). Primary motoneurons in the spinal cord (Eisen et al. 1986; Myers et al. 1986), and interneurons in the hindbrain (Metcalfe et al. 1986; Mendelson, 1986) and spinal cord (Kuwada et al. 1990) have been characterized that can be identified individually, from very early stages in their development. One class of primary sensory neurons, posterior lateral line neurons, has also been characterized (Metcalfe, 1985).

We now show that many, but not all, classes of primary neurons express L2/HNK-1 during their early development, and that they do so in distinctive patterns. Strong and very early expression in RohonBeard neurons and trigeminal ganglion sensory neurons has allowed us to study the development of these cell types in detail for the first time, revealing that both types develop very similarly, and suggesting that they are following a common developmental program. L2/ HNK-1 is present on the axonal growth cones of these sensory neurons, locally on the surface of the hindbrain where the trigeminal growth cones enter the brain, along their central axonal pathway, and on the surface of a prominent central synaptic target contacted by the growth cones, the Mauthner neuron. These are surfaces where adhesive interactions, perhaps mediated by molecules possessing the L2/HNK-1 epitope, could play important roles in axonal guidance and target recognition.

\section{Materials and methods}

\footnotetext{
Embryos

Zebrafish (Brachydanio rerio) eggs were collected from spontaneous spawnings and staged when $4-8$ cells were present in order to estimate the time of fertilization within about $15 \mathrm{~min}$. The embryos were incubated at $28.5^{\circ} \mathrm{C}$; developmental time is presented as $\mathrm{h}$ (hours after fertilization) at this temperature. The stages of individual embryos from $10-24 \mathrm{~h}$ were determined by counting somites (Hanneman and Westerfield, 1989); animals from $24-36 \mathrm{~h}$ were staged according to the position of the migrating primordium of the posterior lateral line (Metcalfe, 1985).

Embryos ranging in age from $10 \mathrm{~h}$ to $65 \mathrm{~h}$ were studied by
}

immunolabeling (see below) with $\mathrm{zn}-12$ (170 embryos) or HNK-1 (129 embryos). Most of these embryos were prepared as whole mounts (274 embryos), but specimens older than $30 \mathrm{~h}$ were sectioned on a cryostat ( 24 embryos); such sections had reduced nonspecific labeling and allowed more detailed study of fine processes.

In other embryos, neurons were retrogradely labeled from their growing neurites with HRP (Metcalfe et al. 1985; Mendelson, 1986) $(n=50)$, or with the fluorescent dye DiI $(n=37)$. Rohon-Beard neurons were also studied after labeling by injecting their precursor blastomeres with fluorescent lineage-tracer dyes (Myers et al. 1986), and inspecting them in the live preparations (Kimmel et al. 1990b).

\section{Measurements of rates of axon elongation}

The rate of axon elongation was determined by measuring the distance from the cell body to the tip of the leading growth cone in embryos of different stages. Distances were measured under the compound microscope using a calibrated reticle and a $\times 40$ objective. The measured distances of axon length were consistent in both live material and fixed embryos after correction for shrinkage.

\section{Antibodies}

The $\mathrm{zn}-12$ monoclonal antibody was generated by one of us (BT) by injecting a mouse with a membrane fraction of adult zebrafish CNS, followed by immunosuppression with cyclophosphamide (Matthew and Patterson, 1983), and then injecting membrane fractions of adult zebrafish CNS again (Trevarrow et al. 1990). The $\mathrm{zn}-12$ monoclonal antibody is a mouse IgG1.

The monoclonal antibody HNK-1 (mouse IgM) was obtained from supernatants of HNK-1 hybridoma cells (American Type Tissue Culture Collection) cultured in RPMI medium (GIBCO) supplemented with $20 \%$ fetal calf serum (Girdlestone and Weston, 1985).

\section{Preparation of zebrafish embryo extract}

Approximately 4000 zebrafish larvae, 3.5 days old, were homogenized on ice in $5 \mathrm{ml}$ of $20 \mathrm{~mm}$ phosphate buffer (pH 7.4), $10 \mathrm{~mm}$ EDTA (ethylenediamine- $\mathrm{N}, \mathrm{N}, \mathrm{N}^{\prime}, \mathrm{N}^{\prime}$-tetraacetic acid), $1 \%$ sucrose, $1 \% \mathrm{NP}-40$, and $100 \mathrm{~mm} \mathrm{NaCl}$. Immediately before homogenization, protease inhibitors were added to the following final concentrations: $1.3 \mathrm{~mm}$ phenylmethylsulfonyl fluoride, $67 \mu \mathrm{g} \mathrm{ml}^{-1}$ aprotitin, $6.7 \mu \mathrm{g} \mathrm{ml}^{-1}$ soybean trypsin inhibitor, $6.7 \mu \mathrm{g} \mathrm{ml}^{-1}$ leupeptin, and $1.3 \mu \mathrm{g} \mathrm{ml}^{-1}$ chymostatin. The homogenate was centrifuged at $10000 \mathrm{~g}$ for $1 \mathrm{~h}$ at $4^{\circ} \mathrm{C}$. The supernatant was stored at $-70^{\circ} \mathrm{C}$

\section{Preparation of zn-12 sepharose}

The zn-12 antibody was coupled to $\mathrm{CNBr}$-activated Sepharose CL-4B (Pharmacia Fine Chemicals) by incubation in bicarbonate buffer ( $\mathrm{pH} 8.3$ ) overnight at $4^{\circ} \mathrm{C}$ with gentle inversion. The remaining reactive groups were blocked by a two hour incubation with $0.2 \mathrm{M}$ glycine ( $\mathrm{pH} 8.0$ ). The affinity sepharose was washed several times with $10 \mathrm{~mm}$ Tris (pH8.0), $140 \mathrm{~mm}$ $\mathrm{NaCl}$ (TS buffer) and resuspended in an equal volume of TS buffer.

\section{Purification of the $z n-12$ antigen}

The $\mathrm{zn}-12$ antigen was purified by the method of Springer (1987). A $100 \mu \mathrm{l}$ sample was thawed on ice and diluted to $1.0 \mathrm{ml}$ with $10 \mathrm{~mm}$ Tris ( $\mathrm{pH} 8.0$ ), $140 \mathrm{~mm} \mathrm{NaCl}$, and $0.1 \% \mathrm{NP}$ 40 (TSN buffer). The extract was precleared using $25 \mu \mathrm{l}$ nonspecific IgG-Sepharose by gentle inversion for one hr at $4^{\circ} \mathrm{C}$. Antigen was isolated by incubation of the precleared extract 
with $100 \mu \mathrm{ln}-12$-Sepharose for one hr at $4^{\circ} \mathrm{C}$. The Sepharose was washed twice with $1.0 \mathrm{ml}$ TSN buffer, twice with $1.0 \mathrm{ml}$ TS buffer, and once with $1.0 \mathrm{ml} 50 \mathrm{~mm}$ Tris ( $\mathrm{pH} 6.8$ ). The antigen was removed from the Sepharose by boiling in $25 \mu$ l SDS sample buffer for five minutes. The sample was then loaded onto SDS-polyacrylamide gels for analysis.

\section{Western blots}

SDS-polyacrylamide gels were transferred to PVDF (polyvinylidene difluoride) membranes (Immobilon, 0.45 pore size, Millipore) for $45 \mathrm{~min}$ (0.8 to $1.2 \mathrm{amps}$ at constant voltage). Primary antibodies were used at a final concentration of $1.7 \mu \mathrm{g} \mathrm{ml}^{-1}$. The antibody binding was visualized by alkaline phosphatase using an ABC-AP kit (Vector Labs).

Preparation of zebrafish extracts for time course assay 10 zebrafish in $40 \mathrm{ml}$ water were homogenized in $8 \mathrm{ml}$ SDS buffer on ice. The homogenate was centrifuged for three minutes in a microfuge. The supernatant fluid was removed and boiled for five minutes. $10 \mathrm{ml}$ of this sample was loaded per lane on a $7 \%$ polyacrylamide gel and transferred to PVDF membranes as above.

\section{Immunolabeling procedure}

Staged embryos were dechorionated, anesthetized with MS222 , and fixed for 6-12 hours in a solution of $4 \%$ paraformaldehyde, $4 \%$ sucrose, and $0.15 \mathrm{M}$ calcium chloride in $0.1 \mathrm{M}$ sodium phosphate buffer, $\mathrm{pH}$ 7.3. The fixed embryos were permeabilized by washing in $0.1 \mathrm{M}$ sodium phosphate buffer, $\mathrm{pH} 7.3$ (PB) for $5 \mathrm{~min}$, washing in distilled water for $5 \mathrm{~min}$, and soaked for $7 \mathrm{~min}$ in $100 \%$ acetone at $-20^{\circ} \mathrm{C}$. The embryos were then rinsed in $\mathrm{H}_{2} \mathrm{O}$ once, then rinsed twice in $\mathrm{BSA} / \mathrm{PB} / \mathrm{DMSO}$ (1\% Bovine Albumin (Sigma) and $1 \%$ dimethylsulfoxide in $\mathrm{PB}$; this is the carrier used in all

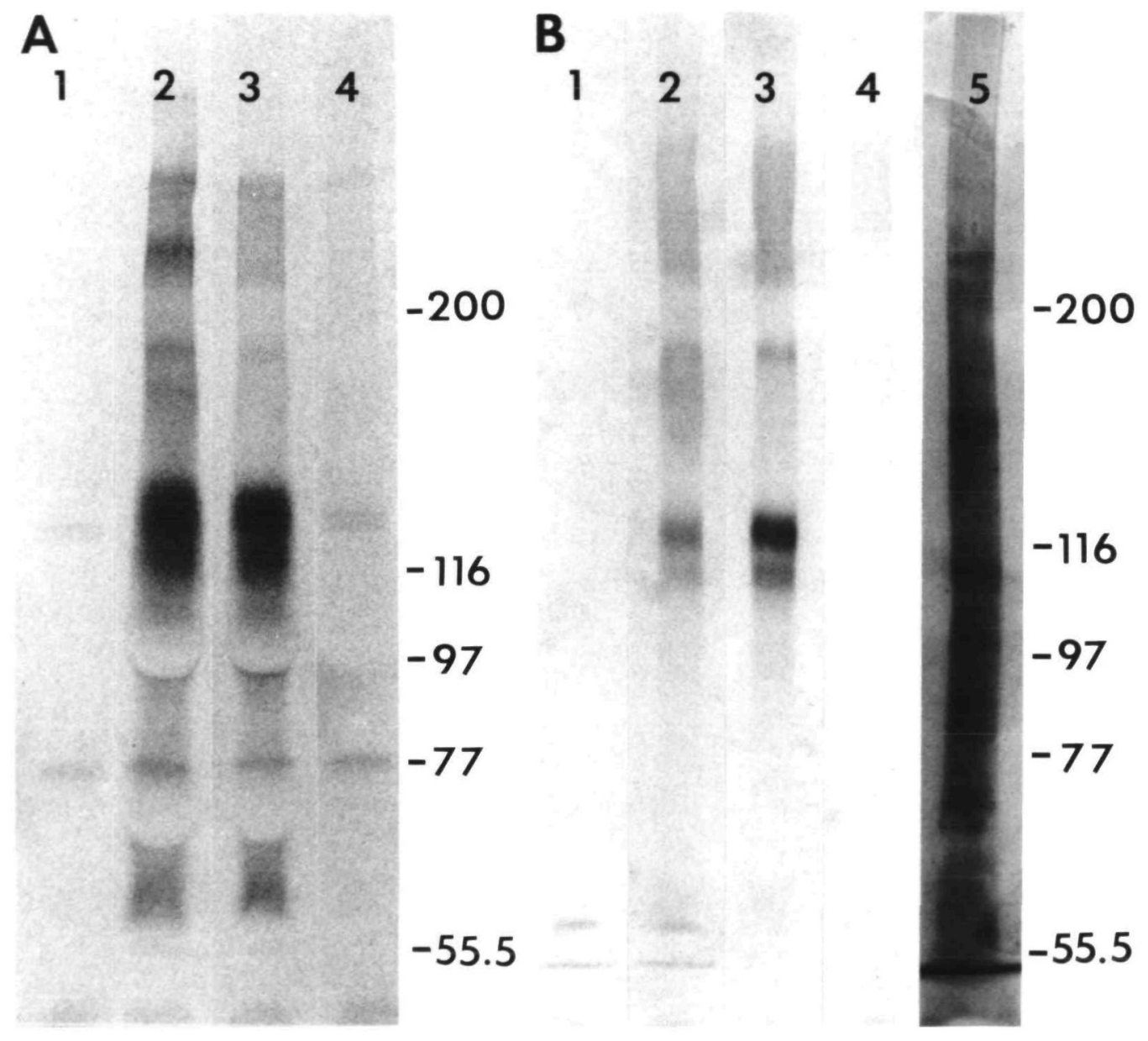

Fig. 1. HNK-1 and zn-12 antibodies recognize the same antigens in zebrafish. (A) Both antibodies show similar immunolabeling patterns in $6 \%$ polyacrylamide gels prepared from zebrafish embryo extract. The lanes labeled with zn- 12 (lane 2) and HNK-1 (lane 3) both show labeled bands at 248,180, 160,149, 93, 64 and $60 \times 10^{3}$ apparent molecular weights as well as diffuse labeling at about 220,125 , and $115 \times 10^{3}$. Lane 1 shows crude embryonic extract labeled with anti-IgG but with no primary antibody, and reveals background labeling at 129,126 , and $79 \times 10^{3}$. Similarly, lane 4 shows crude embryonic extract labeled with anti-IgM in the absence of primary antibody (zn-12 is an IgG, and HNK-1 is an IgM). (B) HNK-1 recognizes zn-12 affinity-purified antigen. Zn-12 antigen was purified by immunoaffinity chromatography from zebrafish extract by immunoprecipitation using $\mathrm{zn}-12$-Sepharose (see Methods). Zn-12 (lane 2) and HNK-1 (lane 3) both recognize bands at 273, 235, 215, 180, 125 (diffuse), 115 (diffuse) and $99 \times 10^{3}$ apparent molecular weights. Lanes 1 and 4 show nonspecific labeling due to the secondary antibodies (anti-IgG and IgM, respectively). Lanes 1 and 2 show a band at $56 \times 10^{3}$ that appears to be the IgG heavy chain (the IgG heavy chain may have been released from the $\mathrm{zn}$ - 12 -Sepharose by $\beta$ mercaptoethanol during the boiling step of purification; see Methods). The total protein pattern is shown by silver staining (lane 5). 
subsequent steps). Non-specific sites were blocked by treating with $2 \%$ normal goat serum (Cooper Biomedical, Inc.) for $30 \mathrm{~min}$ at $20^{\circ} \mathrm{C}$. The embryos were then incubated overnight in the primary antibody (zn-12, or $\mathrm{HNK}-1$, culture supernatant) with $1 \% \mathrm{DMSO}$ at $4^{\circ} \mathrm{C}$, then washed for a total of two hours with three changes of BSA/PB/DMSO. The embryos were then soaked for six hours in secondary antibody $(0.5 \%$ goat anti-mouse $\operatorname{IgA}, \operatorname{IgG}$, and IgM (Cooper Biomedical, Inc.) in $\mathrm{BSA} / \mathrm{PB} / \mathrm{DMSO}$ ) at $20^{\circ} \mathrm{C}$; washed two hours in $\mathrm{BSA} / \mathrm{PB} / \mathrm{DMSO}$; then soaked in PAP $(0.5 \%$ peroxidaseantiperoxidase (Sternberger-Meyer) in BSA/PB/DMSO) overnight at $4{ }^{\circ} \mathrm{C}$, then washed three times in $\mathrm{PB}$ with $1 \%$ DMSO. The peroxidase was histochemically detected by soaking the embryos in $0.05 \%$ diaminobenzidine (DAB, Sigma Chemical Co.) with $1 \%$ DMSO in $0.05 \mathrm{M}$ sodium phosphate buffer, pH 7.3 for 15 min before adding hydrogen peroxide to a final concentration of $0.003 \%$ and incubating the tissue for about 10 to $15 \mathrm{~min}$ (until staining could be seen using a stereomicroscope). The embryos were then washed in $\mathrm{PB}$; then distilled water; then dehydrated through a graded series of ethanols. The dehydrated embryos were cleared using methyl salicylate, and mounted as whole mounts on a slide in Permount (Fisher Scientific Co.) using two coverslips as spacers to prevent crushing.

Sectioned material was prepared by fixing zebrafish embryos as described above; washing in PB; embedding in $1.5 \%$ agar in $0.15 \mathrm{M}$ sucrose; and allowing the blocks of embedded embryos to sink in $30 \%$ sucrose overnight at $4{ }^{\circ} \mathrm{C}$. The agar blocks were then frozen in liquid nitrogen and sectioned at $25 \mu \mathrm{m}$ in a cryostat at $-20^{\circ} \mathrm{C}$. The sections were mounted on subbed slides and dried at $20^{\circ} \mathrm{C}$ overnight. The labeling and staining procedures were as described above, except that antibody incubations were reduced to one hour at $20^{\circ} \mathrm{C}$, with $30 \mathrm{~min}$ washes. After dehydration in graded ethanols, the sections were cleared in xylene and mounted in Permount. HRP and antibody-labeled material was corrected for shrinkage of $20 \%$.

Quail tissue was fixed for 6 hours ( $40 \mathrm{~h}$ quail) or 12 hours (4 day quail) in fixative described above. The tissue was rinsed several times in $\mathrm{PB}$ and stored overnight at $4^{\circ} \mathrm{C}$ in $\mathrm{PB}$. After sinking in $30 \%$ sucrose, the tissue was embedded in OCT compound (Miles laboratories, Inc.), frozen on dry ice and stored at $-70^{\circ} \mathrm{C}$. The embedded embryos were sectioned at $16 \mu \mathrm{m}$, mounted on subbed slides, dried at $20^{\circ} \mathrm{C}$ and stored at $-20^{\circ} \mathrm{C}$. Subsequent labeling, staining and mounting procedures were the same as described above for sectioned zebrafish embryos.

\section{Electron microscopy}

Staged embryos were dechorionated, anesthetized with MS222 , and fixed for one hour in $4 \%$ paraformaldehyde and $0.4 \%$ glutaraldehyde in $\mathrm{PB}$ at $20^{\circ} \mathrm{C}$, then $12 \mathrm{~h}$ in high $\mathrm{pH}$ fix (4\% paraformaldehyde in $0.1 \mathrm{M}$ sodium bicarbonate buffer, $\mathrm{pH} 10.4)$ at $4^{\circ} \mathrm{C}$. The embryos were next washed in $\mathrm{PB}$, then in BSA/PB/DMSO, then soaked for $12 \mathrm{~h}$ at $4^{\circ} \mathrm{C}$ in the $\mathrm{zn}-12$ primary antibody (undiluted culture supernatant) to which $1 \%$ DMSO was added, then washed in BSA/PB/DMSO, then soaked in secondary antibody ( $1 \%$ goat anti-mouse $\mathrm{IgG}$ (Cooper Biomedical, Inc.) in BSA/PB/DMSO) for 6 hours at $20^{\circ} \mathrm{C}$, then washed in BSA/PB/DMSO, and soaked in PAP (1\% mouse peroxidase anti-peroxidase (Cooper Biomedical, Inc.) in BSA/PB/DMSO). The embryos were then washed in $\mathrm{BSA} / \mathrm{PB} / \mathrm{DMSO}$, then in $0.1 \mathrm{~m}$ phosphate buffer ( $\mathrm{pH} 7.3$ ). The peroxidase was histochemically detected by soaking the embryos in $0.05 \% \mathrm{DAB}$ and $0.1 \% \mathrm{DMSO}$ in PB for $20 \mathrm{~min}$, then adding $0.002 \%$ hydrogen peroxide and incubating the tissue for about $15-20 \mathrm{~min}$. The embryos were then washed in
$\mathrm{PB}$, postfixed in $0.2 \%$ osmium tetroxide in $\mathrm{PB}$ for $20 \mathrm{~min}$, washed in $\mathrm{PB}$, dehydrated through ethanols then propylene oxide, and embedded in Epon/Araldite. The embryos were sectioned at $5 \mu \mathrm{m}$, viewed on a Zeiss universal microscope to identify sections of interest, then re-embedded in Epon/ Araldite (Schabtach and Parkening, 1974) and sectioned at about $80 \mathrm{~nm}$. Sections are placed on Formvar-coated grids, stained with uranyl acetate and lead citrate, carbon stabilized and examined with a Phillips CM-12 STEM electron microscope.

\section{Results}

\section{The zn-12 antibody recognizes the L2/HNK-1 carbohydrate}

Previous studies have demonstrated that several monoclonal antibodes, including HNK-1 (Chou et al. 1986), NC-1 (Tucker et al. 1984), and L2 (Kruse et al. 1984), recognize a common carbohydrate moiety, a tetrasaccharide contained in 3-sulfoglucuronyl neolactotetraosyl ceramide (Chou et al. 1986), termed L2/HNK-1. Most of our labeling studies were carried out with a newly generated monoclonal antibody, zn-12, that we show here recogizes the same L2/HNK-1 epitope.

The L2/HNK-1 epitope has been shown to be associated with a variety of cell adhesion glycoproteins (Kruse et al. 1984), and antibodies against it recognize a series of bands and diffuse reactive material in Western blots. Differences in species, age and location in the animal have all been shown to contribute to differences in apparent molecular weights of the immunoreactive material (Tucker et al. 1984). We compared the immu-

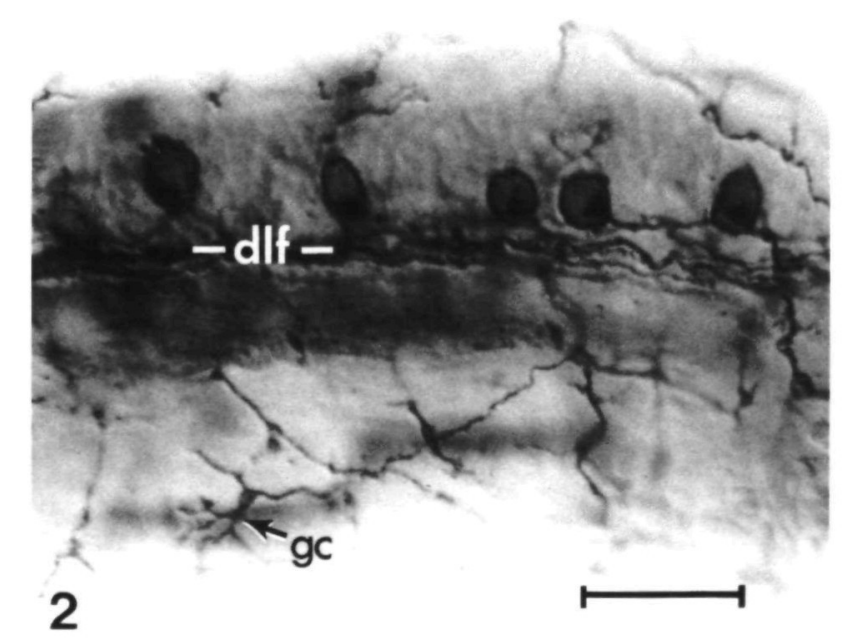

Fig. 2. Zn-12 labels the surface of Rohon-Beard cells, including axons and growth cones, as well as a juxtanuclear cytoplasmic region. Lateral view of a whole mount at $19 \mathrm{~h}$. The Rohon-Beard cells are in a dorsolateral column in the spinal cord. By $20 \mathrm{~h}$, there are $2.3 \pm 0.2$ (mean \pm standard deviation, $n=100$ ) immunolabeled Rohon-Beard cells on each side of each segment, but they are not segmentally arranged. Their central axons are present within the dorsolateral fascicle (dIf) of the spinal cord, and their peripheral fibers are in the skin. A peripheral axonal growth cone $(\mathrm{gc})$ is visible. $\mathrm{Bar}=25 \mu \mathrm{m}$. 
nolabeling patterns of the HNK-1 and $\mathrm{zn}-12$ antibodies on $6 \%$ polyacrylamide gels, prepared from zebrafish embryo extract (Fig. 1A). The Western staining patterns for both zn-12 and HNK-1 of crude embryonic zebrafish extract are similar. Furthermore, HNK-1 antibody recognizes affinity-purified $\mathrm{zn}-12$ antigen, in a pattern indistinguishable from $\mathrm{zn}-12$ antibody itself (Fig. 1B). Thus, the L2/HNK-1 tetrasaccharide appears to be present in all of the bands recognized by $z n-$ 12 in the zn-12 affinity-purified extract.

Direct evidence that $\mathrm{zn}-12$ recognizes the L2/HNK-1 epitope itself was provided by examining $\mathrm{zn}-12 \mathrm{immu}-$ noreactivity against a variety of lipids, by immunoblot analysis (performed by Jungalwala and Chou, who kindly made their results available to us). $\mathrm{Zn}-12$ stained $20 \mathrm{ng}$ of the purified L2 glycolipid (3-sulfoglucuronyl neolactotetraosyl ceremide, Chou et al. 1986), but failed to stain sulfatide $(4 \mu \mathrm{g})$, paragloboside $(1.5 \mu \mathrm{g})$, a $15 \mu \mathrm{g}$ mixture of gangliosides (including GM1, GM2, GM3, LM1, GD1a, GD1b and GT1b; Künemund et al. 1988), glucocerebroside, ceramide lactoside, ceremide trihexoside, globoside, asialoGM1, and the Forssman antigen. Thus, in this assay, zn- 12 reacts just like HNK1 with these glycolipids and appears to recognize the L2/HNK-1 carbohydrate specifically.

As expected from the above analyses, we found that HNK-1 and zn-12 immunolabeling patterns were identical in quail embryos (data not shown), as well as in zebrafish embryos. Labeling of the quail material was as previously reported (Vincent et al. 1983; Vincent and Thiery, 1984), and labeling of zebrafish is described below.

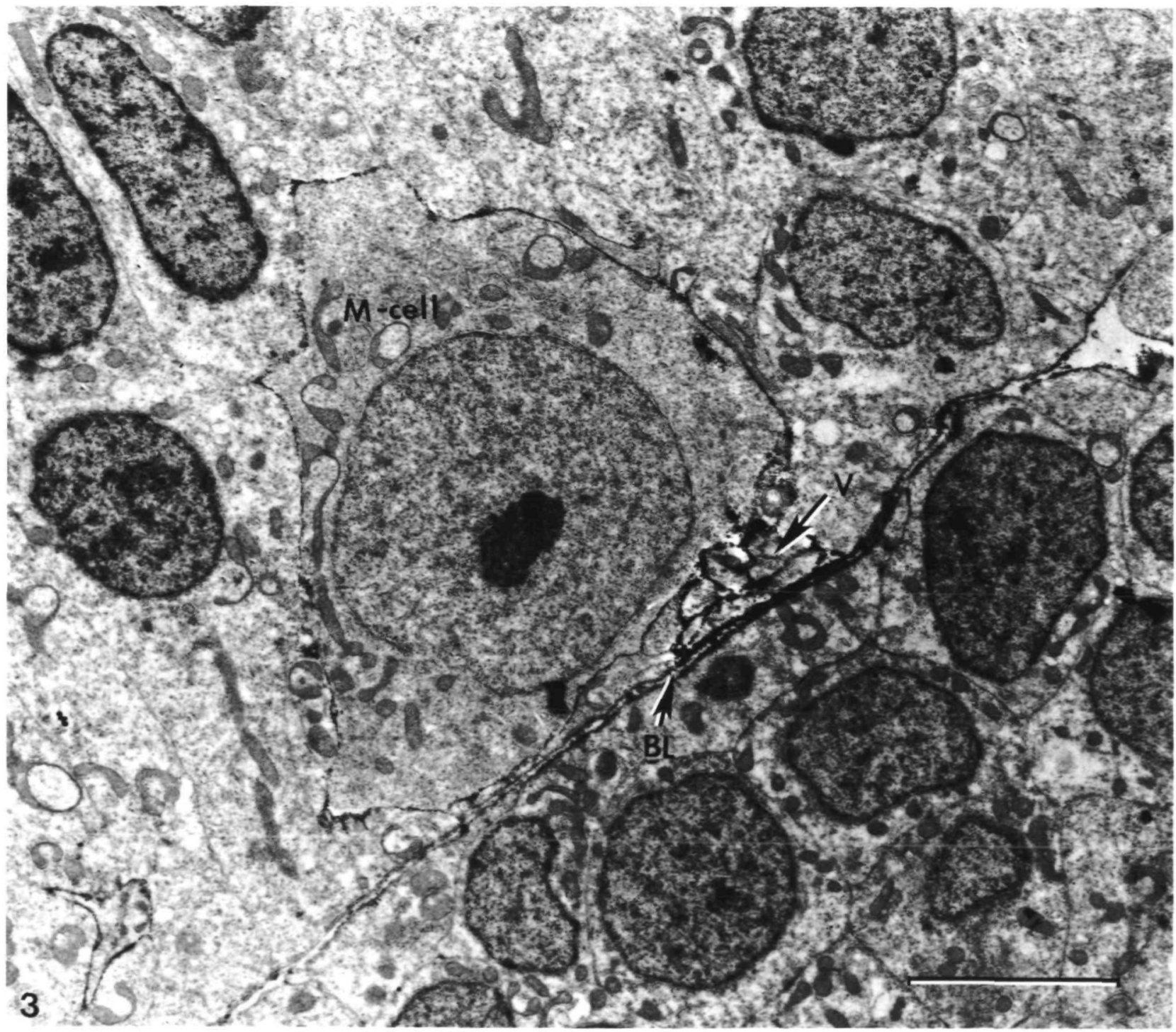

Fig. 3. Electron micrograph of a transverse section from a $19 \mathrm{~h}$ embryo labeled with zn-12. Antigen is present on the surface of the trigeminal sensory axons (V) and the Mauthner neuron (M-cell), which is a synaptic target of the trigeminal axons (Kimmel et al. 1990a). The basal lamina (BL) of the brain surface underlying the growing trigeminal sensory axons is also immunoreactive. The Mauthner cell was identified in $5 \mu \mathrm{m}$ sections on the basis of its large size and characteristic location in the hindbrain, and the section was re-embedded and resectioned for electron microscopy. Bar $=5 \mu \mathrm{m}$. 
Table 1. Onset of zn-12 immunoreactivity in zebrafish embryos ${ }^{1}$

\begin{tabular}{|c|c|}
\hline $12-14 h:$ & Notochord surface ${ }^{2}$ \\
\hline $14-16 \mathrm{~h}:$ & $\begin{array}{l}\text { Trigeminal ganglion } \\
\text { Rohon-Beard neurons } \\
\text { Neuroepithelial cells of rostral hindbrain }{ }^{3}\end{array}$ \\
\hline $16-18 \mathrm{~h}:$ & $\begin{array}{l}\text { Nucteus of the medial longitudinal fascicle } \\
\text { Hindbrain reticulospinal neurons } \\
\text { Acoustuco-vestibulo (VIII) ganglion } \\
\text { Posterior lateral line ganglion } \\
\text { Anterior lateral line ganglion } \\
\text { Spinal commissural neurons }\end{array}$ \\
\hline $18-19 \mathrm{~h}$ & $\begin{array}{l}\text { Forebrain bcell groups } \\
\text { Trunk neural crest cells }^{6} \\
\text { Pronephric duct }^{7} \\
\text { Trunk muscle }^{8}\end{array}$ \\
\hline $22-24 h:$ & $\begin{array}{l}\text { Primary motoneurons of spinal cord } \\
\text { Posterior commissure }{ }^{10} \\
\text { Pronephros }\end{array}$ \\
\hline $30-36 h$ & $\begin{array}{l}\text { Cerebellum } \\
\text { Glossopharyngeal ganglion } \\
\text { Facial ganglion }\end{array}$ \\
\hline $36-65 h:$ & $\begin{array}{l}\text { Many CNS neurons }{ }^{11} \\
\text { Neural retuna }{ }^{12} \\
\text { Vagal ganglion }\end{array}$ \\
\hline
\end{tabular}

${ }^{1}$ Not all labeled cells are represented in this table, although almost all of the cells that become labeled in the first $30 \mathrm{~h}$ are listed.

${ }^{2}$ At $12-14 \mathrm{~h}$, we occasionally observed weak labeling of a narrow midsagittal stripe along the dorsal and ventral surface of the notochord in the trunk region

${ }^{3}$ See Fig. 5B.

${ }^{4}$ Labeled axons cross the midline in the trunk region, but labeled cell bodies were not detected.

${ }^{5}$ Ventrolateral cell groups in both the telencephalon and diencephalon begins to be labeled at $18 \mathrm{~h}$, by $19.5 \mathrm{~h}$ labeled fibers connect the forebrain cell groups and descend to the nucleus of the medial longitudinal fascicle in the midbrain formung a continuous, bilaterally symmetric, labeled pathway from rostral telencephalon to the spinal cord. For a detailed descripuon of these cell groups, see Wilson et al. 1990.

${ }^{6}$ Putative neural crest cells were identified by their positions along the migration pathways in the trunk (either medial or lateral to the somites) and by their morphology (flat cells with irregular borders suggestive of actively migratıng cells, Greg Bobrowicz, unpublished observations). Such cells were stained only rarely, and were lightly labeled.

${ }^{7}$ The pronephric duct generally contained small patches of 4-5 labeled cells, although in one $18 \mathrm{~h}$ embryo all of the duct cells appeared to be labeled.

${ }^{8}$ The earliest labelıng of trunk myotomes occurs as surface labeling of ventral muscle fibers in the first myotome at $18.5 \mathrm{~h}$. By $19.5 \mathrm{~h}$, muscle fibers and the transverse myosepta (boundary between myotomes) of the first five myotomes are labeled in a rostro-caudal gradient of intensity (Fig. 5). Within each myotome, dorsal and ventral fibers stain more intensely than fibers in the region of the horizontal myoseptum (boundary between the dorsal and ventral muscle fibers of each myotome). By $65 \mathrm{~h}$, muscle fibers of the trunk show intense surface labeling except medially at the horizontal myoseptum. Labeled elongate cells were occasionally observed in the horizontal myoseptum; however, the presence, frequency and distnbution of these cells varied from animal to anımal.

${ }^{9}$ Primary motoneurons are identified on the basis of their axonal pathway and the positions of their somata as described previously (Eisen et al. 1986; Westerfield et al. 1986). Ventral roots begin to be labeled at $22 \mathrm{~h}$. Within the spinal cord, labeling of the cytoplasmic region is evident in the positions of the pnmary motoneurons, although labeling of the cell surface was weak (see Fig. 10).

${ }^{10}$ The nucleus of the postenor commissure and the nucleus of the medial longitudinal fascicle are contiguous and indistingushable at the early stages examined. These neurons are located bilaterally on the ventrolateral floor of the midbrain and are present as longitudinal columns of about 8-10 cells that begin to be labeled at about $17 \mathrm{~h}$. The first axons to emerge from this cell group arise from caudal cells in the group and grow caudally along the floor of the brain to pioneer the medial longitudinal fascicle in the rostral hindbrain before encountering axons of hindbrain reticulospinal neurons. Fibers forming the posterior commissure begin to grow dorsally from the rostral end of the labeled cell group at about $23 \mathrm{~h}$.

${ }^{11}$ At $36 \mathrm{~h}$, only about $10 \%$ of the neurons in the CNS are labeled, but by $65 \mathrm{~h}$ we estimate that about $90 \%$ are labeled.

${ }^{12}$ At $36 \mathrm{~h}$, there is weak surface labeling of some cells in the ganglion cell layer. By $65 \mathrm{~h}$ there is strong labeling of cells in all of the layers (both nuclear and plexiform) except for the absence of label in rod and cone outer segments.

\section{Cellular localization and time course of L2/HNK-1 expression}

Previous in vitro immunolabeling studies have shown that the L2/HNK-1 carbohydrate is present on the surfaces of a variety of cell types in quail, including neurons (Vincent et al. 1983). Examination of both the zn-12 and HNK-1 immunolabeling patterns in zebrafish embryos reveals a characteristic outlining of the somata of labeled cells as well as more or less complete labeling of the cell processes, including the axon and growth cones (Fig. 2). The outlining is particularly evident on larger cells, such as Rohon-Beard neurons and myotubes. The cell surface localization of the antigen is confirmed by examination of $\mathrm{zn}-12$ immunolabeled embryos with electron microscopy (Fig. 3).

In addition to the cell surface staining, light microscopy reveals an intensely labeled cytoplasmic region that is located near the nucleus (Fig. 2). Although the specific immunoreactive organelle has not been identified (since we have not observed the cytoplasmic staining in embryos prepared for electron microscopy), the developmental onset of this juxtanuclear cytoplasmic staining precedes the expression of the antigen on the cell surface.

Western blot analyses with the zn-12 antibody revealed that $\mathrm{zn}-12$ antigen is detectable during the first day of embryogenesis, and then increases in level, reaching a plateau in the young larva at 4 days (data not shown). In agreement, immunocytochemical labeling is first detected at about $13 \mathrm{~h}$, and during embryogenesis more and more cell types begin expression (Table 1), such that by about $65 \mathrm{~h}$, many (perhaps most) neurons in the embryo are immunopositive. In addition, some non-neural cells also become immunolabeled.

\section{Development of Rohon-Beard and trigeminal ganglion neurons}

The earliest neurons to express the L2/HNK-1 tetrasaccharide are primary sensory neurons that mediate touch sensitivity; the Rohon-Beard neurons of the spinal cord and trigeminal ganglion neurons in the head (Fig. 4). Both show the same early, intense immunolabeling pattern, which is distinct from the immunolabeling pattern of most other neurons in the embryo (see below). This has permitted us to study their early development, which previously has not been well characterized.

Trigeminal sensory neurons are bipolar neurons found in compact ganglia located on both sides of the head, lateral to the midbrain, and between the developing eye and otic vesicle. By $24 \mathrm{~h}$, there are about 20 neurons in each ganglion. Each neuron has a single central axon that extends into the hindbrain and a peripheral axon that arborizes in the skin of the head. Rohon-Beard neurons are among the largest and most readily recognized neurons of the embryonic spinal cord (Figs 2 and 4), and can be identified in the living embryo using Nomarski optics (Grunwald et al. 1988). Their somata average $12.8 \pm 1.9 \mu \mathrm{m}$ in diameter (meanIstandard deviation, $n=100$ ) and are located in a continuous dorsolateral longitudinal column in the 


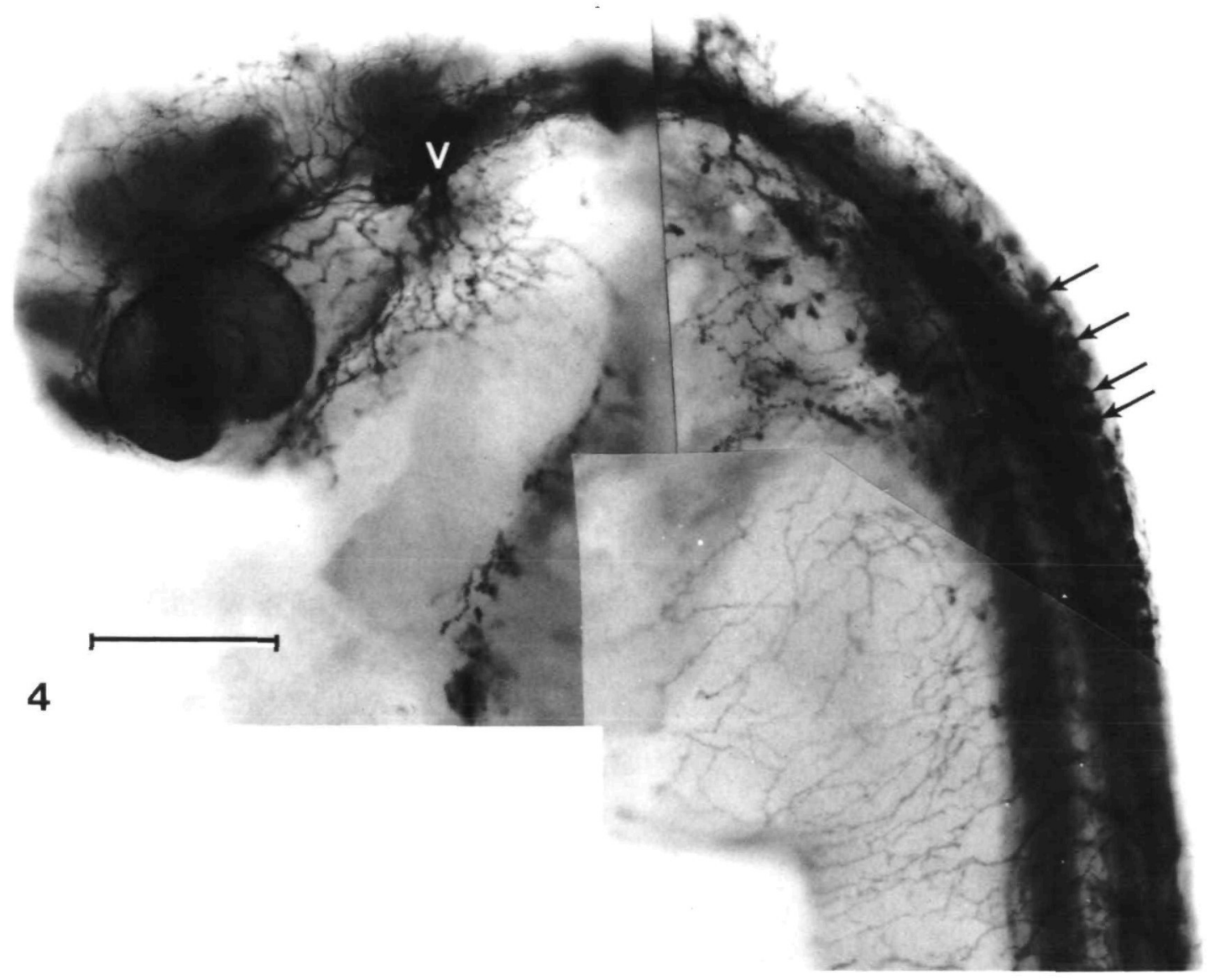

Fig. 4. Photomontage of a $25 \mathrm{~h}$ embryo stained with the $\mathrm{zn}-12$ antibody in a whole-mount preparation. The trigeminal sensory ganglion (V) is located caudal to the developing eye, and Rohon-Beard neurons (arrows on some rostral ones) are distributed along the spinal cord. The stained fibers on the head and rostral yolk sac are from trigeminal neurons, while the fibers on the trunk and remainder of the yolk sac are from Rohon-Beard neurons. Bar $=100 \mu \mathrm{m}$.

dorsal third of the spinal cord. Rohon-Beard neurons have both an ascending and descending central axon in the dorsolateral fascicle (Fig. 2), and also one or more peripheral axons (see below).

The first detectable expression of the L2/HNK-1 epitope occurs at $14 \mathrm{~h}$ in both the compact cluster of trigeminal ganglion neurons and the Rohon-Beard neurons, which at this stage are distributed sparsely throughout the length of the spinal cord, extending nearly to the tail bud. Labeling is first restricted to the juxtanuclear cytoplasm (Fig. 5A); by $16 \mathrm{~h}$, the surfaces of the neurons become labeled (Fig. 5B) and remain labeled to the latest times studied $(65 \mathrm{~h})$. Immunolabel is present on the entire surface of the neurons including their developing axons (Fig. 5C), which begin to grow at $16.5 \mathrm{~h}$, about one-half hour after surface immunolabeling.

\section{Peripheral axons}

The peripheral axonal arbors of trigeminal and RohonBeard neurons are labeled strongly as they develop, rapidly branching over the lateral surface of the embryo in a period of about three hours, and forming a complementary pattern such that the head region and rostral portion of the yolk sac are innervated by trigeminal sensory neurons, while the remainder of the embryo is innervated by Rohon-Beard neurons (Fig. 4). At least some of the peripheral axons appear to be closely associated with the periderm (the outermost layer of the skin), since, in the trunk region, a migrating cell mass called the primordium of the posterior lateral line separates the inner epidermis from the outer periderm (Metcalfe, 1985), and the peripheral Rohon-Beard fibers are present lateral to (outside of) this primordium. The axons of individual cells branch and cross over neighboring processes extensively in both systems. The peripheral arbors of Rohon-Beard neurons are not segmentally restricted since the arbor of a single neuron may extend over 6 myotomes (Fig. 6). However, the peripheral arbors do appear to be restricted to one side of the animal, since branches have not been observed to cross either the dorsal or ventral midline.

The first peripheral Rohon-Beard axons are labeled in a generally rostrocaudal sequence, although individual axons may emerge out of sequence. The periph- 
eral axon may emanate from different locations on a Rohon-Beard cell, including the cell body itself, or either the ascending or descending central axon, and as far as $50 \mu \mathrm{m}$ from the soma. Occasionally, two peripheral axons emerge from a single cell (Fig. 6). The peripheral axons do not leave the spinal cord via a discrete dorsal root; individual axons grow to the dorsal median septum, and exit the spinal cord independently of neighboring axons.
Growth cones of the peripheral neurites of developing trigeminal sensory neurons and Rohon-Beard cells appear morphologically similar. They are complex, with large flattened lamellipodia and numerous filopodia that may be over $10 \mu \mathrm{m}$ long (Figs 2, 7).

\section{Central axons}

The central axons of trigeminal neurons emerge from the caudal pole of the ganglion and enter the brain at
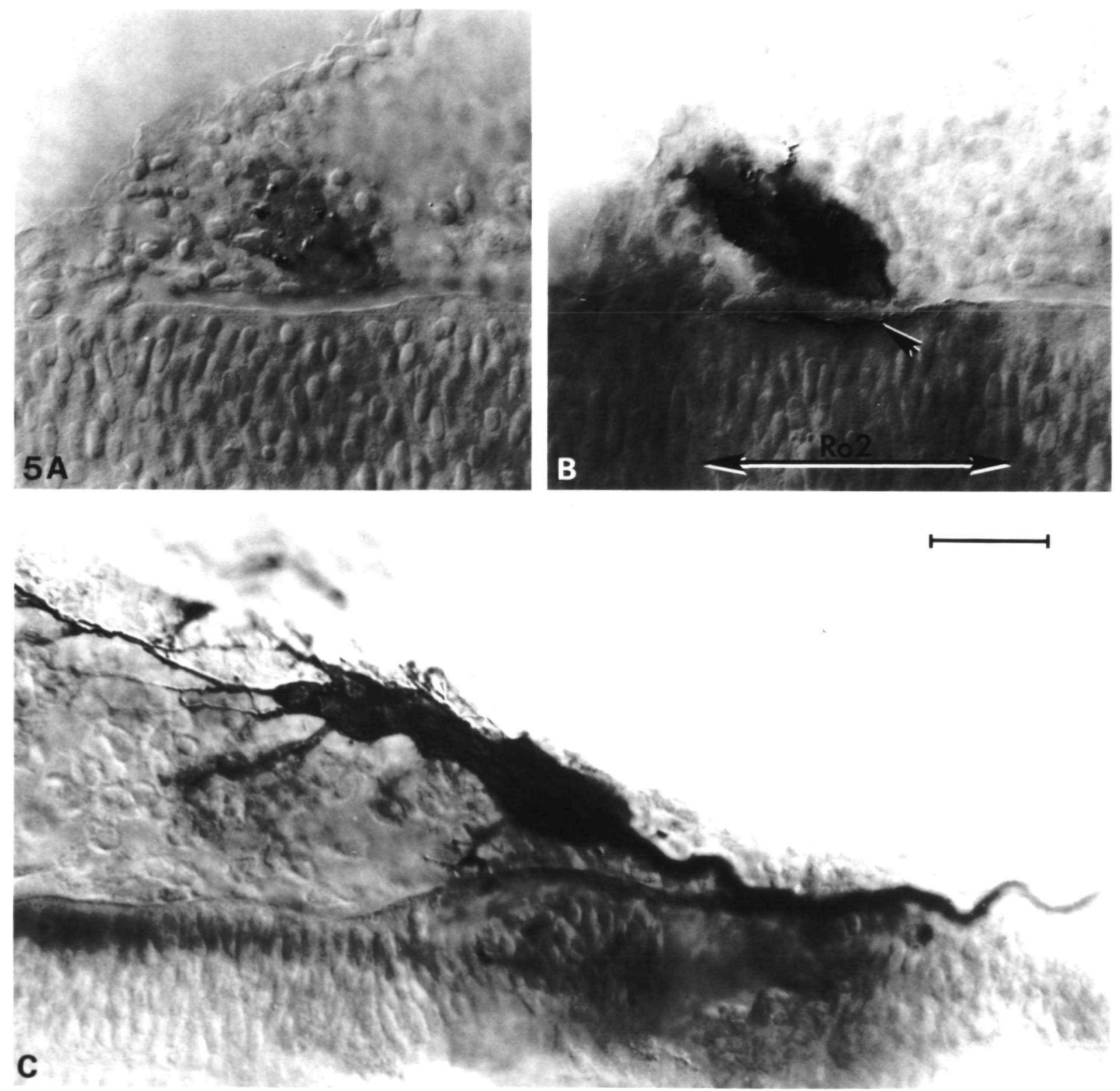

Fig. 5. Zn-12 labeling in the trigeminal sensory ganglion of zebrafish embryos at $14 \mathrm{~h}(\mathrm{~A}), 16 \mathrm{~h}(\mathrm{~B})$ and $22 \mathrm{~h}(\mathrm{C})$. The first immunolabeling appears as dense cytoplasmic patches by $14 \mathrm{~h}$ (A) located lateral to the midbrain, in the region where the trigeminal ganglion will soon develop. Two hours later (B), trigeminal sensory axons begin to grow into the central nervous system as well as in the periphery, and the surfaces of these neurons are immunoreactive. Immunolabeling is also seen specifically on the surface (arrowhead) of the Ro2 segment (Metcalfe et al. 1986; Hanneman et al. 1988) of the hindbrain (arrows). Electron microscopy shows that this surface immunolabeling is localized to the basal lamina (as in Fig. 3). We occasionally observed diffuse immunolabeling of the caudal halves of the Ro2 and Ro1 (rostral to Ro2) hindbrain segments, as in this embryo. By $22 \mathrm{~h}(\mathrm{C})$, both the central and peripheral axons have grown considerably and remain strongly labeled with $\mathrm{zn}-12$. Rostral is to the left, and lateral is to the top. Bar $=25 \mu \mathrm{m}$. 


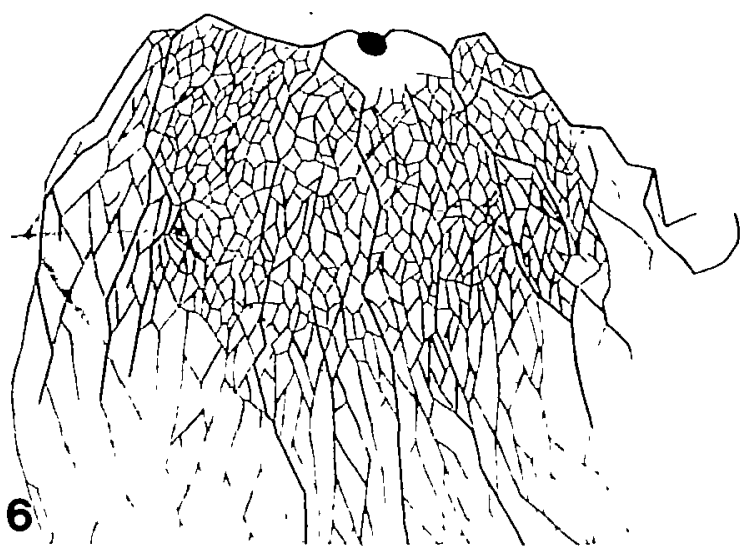

Fig. 6. The peripheral axons of individual Rohon-Beard neurons form very large, dense networks. This drawing is of the peripheral arbor of an isolated Rohon-Beard neuron labeled with rhodamine-dextran. The arbor of this one cell extended over 6 segments longitudinally (myosepta are shown lightly shaded in gray), and from the dorsal to the ventral midline on this one side. No branches could be detected crossing the midline to the opposite side of the embryo.

the second hindbrain segment (Ro2: Hanneman et al. 1988 ) at about $16.5 \mathrm{~h}$. In the central nervous system, the growth cones descend along a longitudinal pathway termed the lateral longitudinal fascicle (llf) in the hindbrain and the dorsolateral fascicle (dlf) in the spinal cord (Metcalfe et al. 1986), to reach to the level of the eighth myotome by $28 \mathrm{~h}$ (Fig. 8 ). The leading growth cone generally bears several small filopodia. Trailing growth cones are observed at irregular intervals (on the order of $50 \mu \mathrm{m}$ apart), and usually are closely associated with the leading fiber.

Descending central fibers of the trigeminal ganglion neurons and ascending central axons of Rohon-Beard neurons grow through the hindbrain at the same rapid rate of about $100 \mu \mathrm{m} \mathrm{h}^{-1}$, five times that of posterior lateral line axons (Fig. 9), which also project directly into the hindbrain. At about $19 \mathrm{~h}$, the first growth cones of the descending trigeminal and ascending RohonBeard fibers approach one another and meet within the sixth (Mi3) hindbrain segment (Fig. 10). Since no other axons have been observed to grow at earlier times with any of our labeling procedures, we suspect that the leading axons are pioneering axons; the trigeminal axons pioneer the llf in the rostral and middle hindbrain regions, and the Rohon-Beard fibers pioneer the dlf in the spinal cord (see also Kuwada, 1986) and the llf in the caudal hindbrain. After meeting, the fibers of the two systems continue to grow in opposite directions along this very narrow pathway, which is the most ventral of three longitudinal sensory tracts found in the embryonic hindbrain (Metcalfe, 1989).

We observed two interesting aspects of L2/HNK-1 expression along the central course of the trigeminal axons. First, at $16 \mathrm{~h}$, which is before axogenesis, the lateral surface of the Ro2 hindbrain segment becomes immunolabeled (Fig. 5B). This is where the labeled trigeminal axons, which originate just lateral to this position, will enter the brain about one-half hour later. Electron microscopy (not shown) reveals that the immunolabeling is localized to the basal lamina surrounding the brain. Second, in older embryos, electron microscopy of the hindbrain and spinal cord revealed immunolabeling of the brain surface that overlies the lateral longitudinal fascicle, the central pathway taken by these axons (Fig. 3). We have not determined whether this immunoreactivity precedes the presence of the first growth cones in this tract, as it does on the brain surface where the axons initially enter.

Molecules that carry the L2/HNK-1 epitope have been implicated in neuromuscular synapse formation (Landmesser, 1988) and, for this reason, it is interesting that an identified central synaptic target of the trigeminal axons, the Mauthner neuron, expresses $\mathrm{zn}-12$ immunoreactivity on its surface at the time initial contacts are made (Kimmel et al. 1990a), and including the location where they are made (Fig. 3).

\section{Expression of L2/HNK-1 is cell-type specific}

As described above, trigeminal and Rohon-Beard primary sensory neurons begin to express the L2/HNK1 epitope long before axogenesis, and come to express it in a distributed pattern over their surfaces. We have observed other temporal-spatial patterns of expression that vary according to the functional type of the primary neuron. Expression patterns have recently been described for the forebrain (Wilson et al. 1990) and hindbrain neuromeres (Trevarrow et al. 1990), and will not be described further here.

Reticulospinal neurons, which are interneurons in the midbrain nucleus of the medial longitudinal fascicle and in the hindbrain (Metcalfe et al. 1986), become immunoreactive between 16 and $18 \mathrm{~h}$, about the time they initiate axons. At $18 \mathrm{~h}$, there are about 8 labeled midbrain reticulospinal neurons in a single longitudinal column on each side of the midline, and their axons extend into the first hindbrain segment. At $17.5 \mathrm{~h}$, i.e. preceding the arrival of the axons from the midbrain, one or more neurons in each of the first six hindbrain segments (see Mendelson, 1986) are first labeled, and have axonal growth cones (see also Kuwada, 1987). The first reticulospinal axonal outgrowth appears to occur nearly simultaneously in all hindbrain segments, and for both ipsilaterally and contralaterally projecting axons (Mendelson and Kimmel, 1986). As compared with Rohon-Beard and trigeminal sensory neurons, the detection of L2/HNK-1 expression is delayed in reticulospinal axons. Their eventual labeling is also less intense but, as shown in Fig. 3, it is distributed over the cell surface, like that of the Rohon-Beard and trigeminal neurons.

In contrast, immunolabeling of primary motoneurons of the spinal cord and posterior lateral line ganglion cells appears as heavy immunolabeling of the juxtanuclear cytoplasm, very weak labeling of the surface of the somata, and strong labeling of the growth cones and distal axonal regions (Fig. 11). The earliest labeling seen in primary motoneurons occurs at about $22 \mathrm{~h}$, 
17

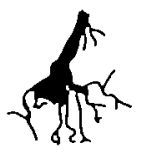

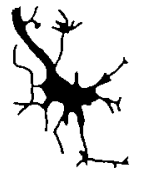

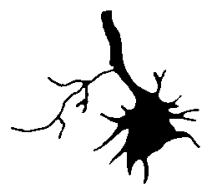
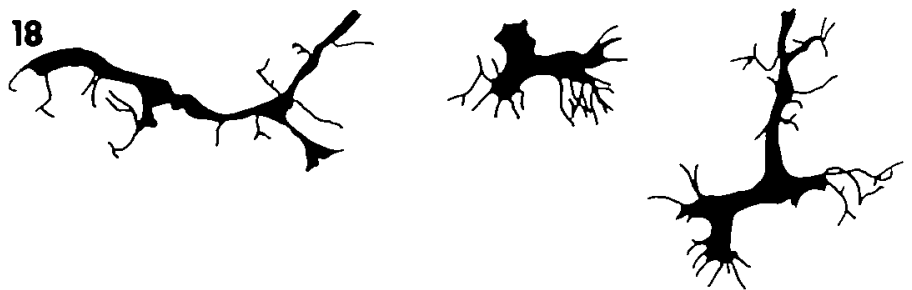

20

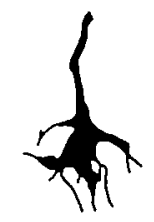

22

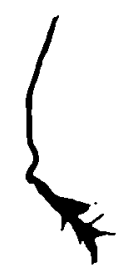<smiles>CCCC(C)(C)C</smiles>

24<smiles>CCCCC(C)C(C)(C)C</smiles>
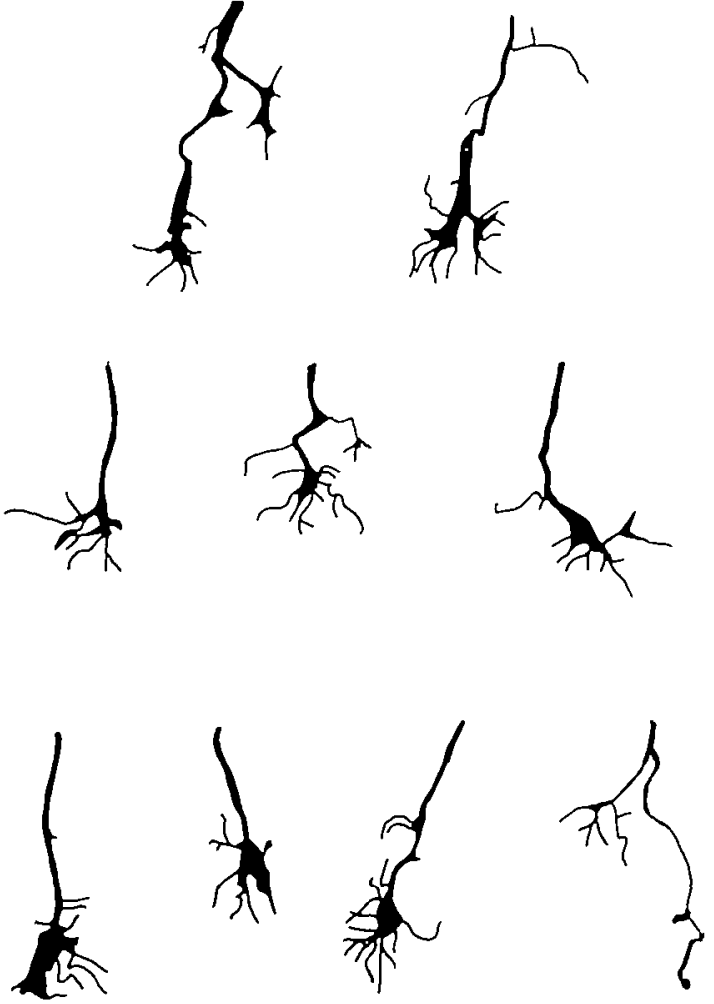
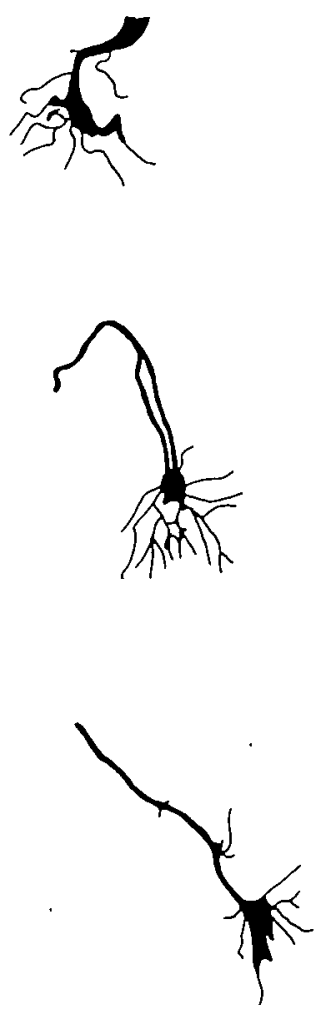

Fig. 7. The growth cones of Rohon-Beard neurons are large and distinctive. These camera-lucida drawings are a sampling of representative growth cones from 17 to $24 \mathrm{~h}$ embryos (age indicated on left). All have broad, flattened lamellipodia and numerous filopodia. $\mathrm{Bar}=10 \mu \mathrm{m}$. which is at least 4 hours after their axons begin to grow (Myers et al. 1986; Eisen et al. 1986). Similarly, immunolabeling of posterior lateral line ganglion cells does not occur until about $20 \mathrm{~h}$, about 2 hours after axonal outgrowth (Metcalfe, 1985). Thus, the antigen does not become detectable in these cell types until several hours after the onset of axonal outgrowth, and the immunolabeling is weaker than observed in trigeminal and Rohon-Beard sensory neurons.

One class of interneurons of the caudal hindbrain and rostral spinal cord, called ic cells (for their ipsilateral and caudal axons), are not immunoreactive at the times we have examined. These neurons have previously been shown to be among the earliest hindbrain neurons to grow axons caudally in the medial longitudinal fascicle (Mendelson, 1986), and at early times show intense immunoreactivity with the $\mathrm{zn}-1$ antibody (Fig. 12). However, other neurons taking this same pathway, particularly reticulospinal neurons, are immunoreactive at this developmental stage.

\section{Discussion}

In this report, we have described expression of the L2/HNK-1 epitope by developing primary neurons in zebrafish, and have used the strong and early labeling observed of two classes of the neurons, Rohon-Beard and trigeminal sensory neurons, to describe their early morphogenesis. 


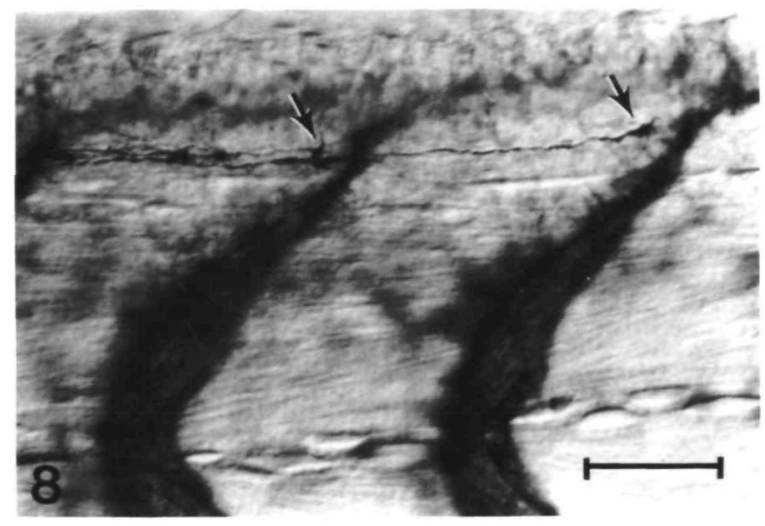

Fig. 8. Central descending trigeminal fibers extend to the level of the eighth myotome at $28 \mathrm{~h}$. These HRP-labeled fibers terminate in small growth cones (arrows). The leading fiber is near the level of the caudal border of the eighth myotome. The axons descend along the lateral surface of the spinal cord in the dorsolateral tract. Myosepta (broad diagonal bands) are nonspecifically labeled. Lateral view, rostral is to the left. Bar $=25 \mu \mathrm{m}$.

\section{L2/HNK-1 expression}

We observed two cellular compartments of antigen expression; a cytoplasmic compartment and the cell surface. The cytoplasmic immunolabeling is juxtanuclear, and we suspect it is in the Golgi apparatus, but have not confirmed this by electron microscopy. The surface labeling is demonstrated here by electron microscopy, and is consistent with previous in vitro immunolabeling studies (Vincent et al. 1983). These data suggest that the antigen is formed in the Golgi apparatus, and is then transported to the cell surface. The antigen is expressed most strongly at the growth cones and distal axonal segments of primary motoneurons and posterior lateral line sensory neurons, suggesting that adhesive molecules with which HNK-1 is associated may be preferentially transported to the distal axon. Other types of primary neurons, in which expression is stronger and is detected earlier, do not show such localized expression, but do show strong labeling of their growth cones. Such cellular distributions are consistent with the epitope, or molecules with which it is associated, having an adhesive role (Künemund et al. 1988) during axonal growth and synapse formation.

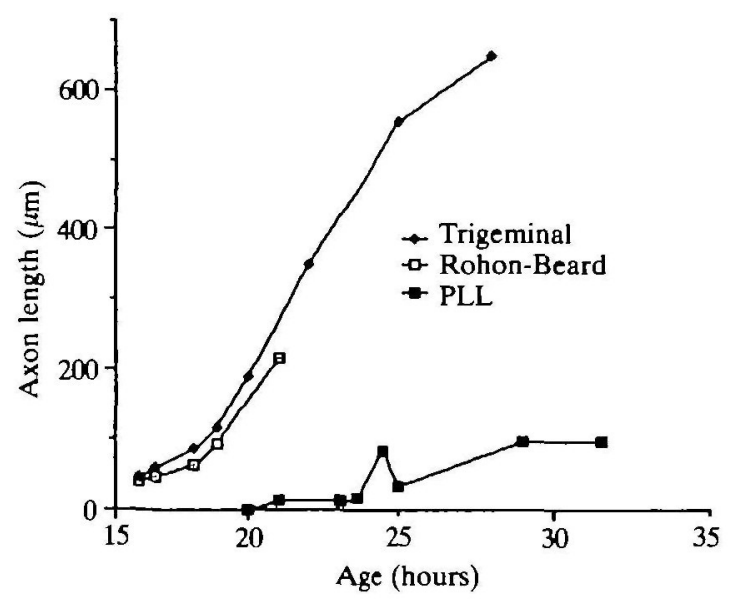

Fig. 9. Axons of trigeminal and Rohon-Beard neurons elongate at nearly the same rapid rate compared to the slower posterior lateral line fibers that grow through the same region at a later time. Trigeminal sensory, RohonBeard, and posterior lateral line axon lengths are plotted as a function of time post fertilization. Each data point represents the mean of several observations (see Methods), thus the exact shape of each curve may not represent the actual time course of growth of individual fibers (for example, pauses at characteristic locations could be obscured by averaging). The end points of each curve do not represent the termination of growth, but only the limits of the data set. For example, Rohon-Beard neurons could only be measured in $\mathrm{zn}-12$ labeled material at times before they met with the descending trigeminal neurons since they occupy the same fiber tract (see Fig. 10). Trigeminal neurons, on the other hand, were easily labeled with HRP even at $28 \mathrm{~h}$, thus the trigeminal curve contains later data points.

A function in axon growth is also suggested by the observations that trigeminal sensory neurons, spinal Rohon-Beard neurons and primary reticulospinal neurons (Kimmel and Westerfield, 1990) express the antigen on their axonal growth cones from the time the growth cones are initiated. We did not detect antigen expression on one particular class of early neurons, ic cells, at a time when we knew from previous studies that they are growing axons (Mendelson, 1986). This suggests that the epitope may not be required for axonal growth of all primary neurons, even though it may be for some of them. A guidance function of L2/HNK-1 antigen is supported by the observations that immuno-
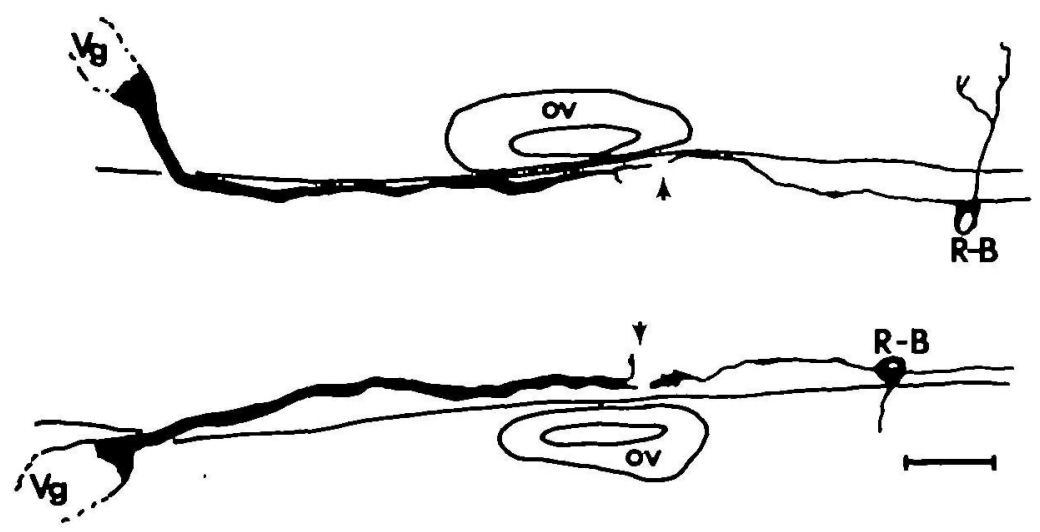

Fig. 10. Descending trigeminal fibers meet ascending Rohon-Beard fibers at the caudal margin of the otic vesicle (ov). Terminal growth cones (arrows) originating from the trigeminal ganglion (Vg) and Rohon-Beard neurons (R-B) are separated by less than $10 \mu \mathrm{m}$ on both sides of the hindbrain. Drawing of an embryo labeled with $\mathrm{zn}-12$ at $19 \mathrm{~h}$. Horizontal view, rostral is to the left. $\mathrm{Bar}=30 \mu \mathrm{m}$. 


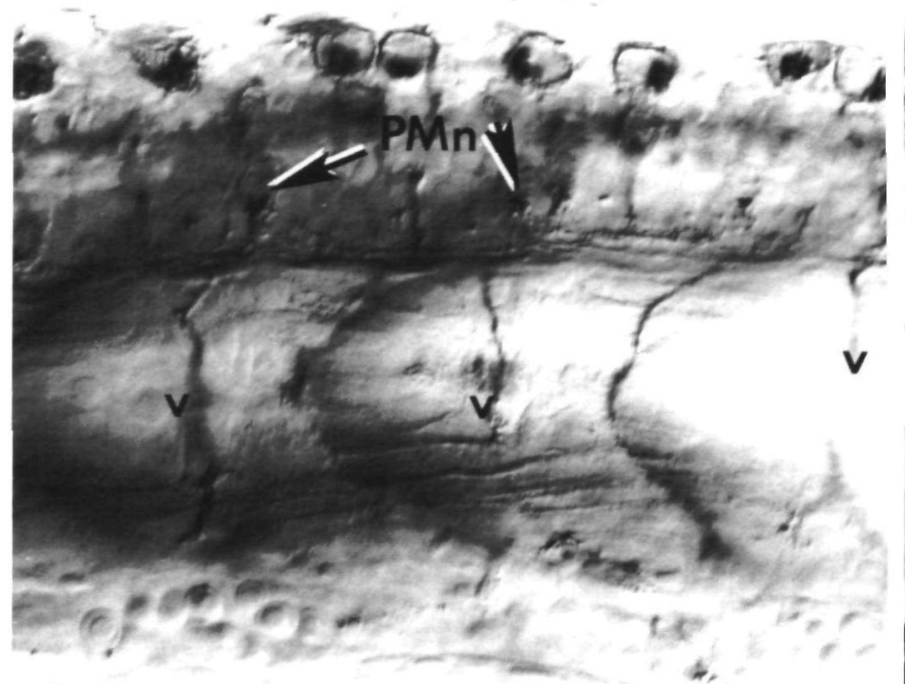

$11 \mathrm{~A}$

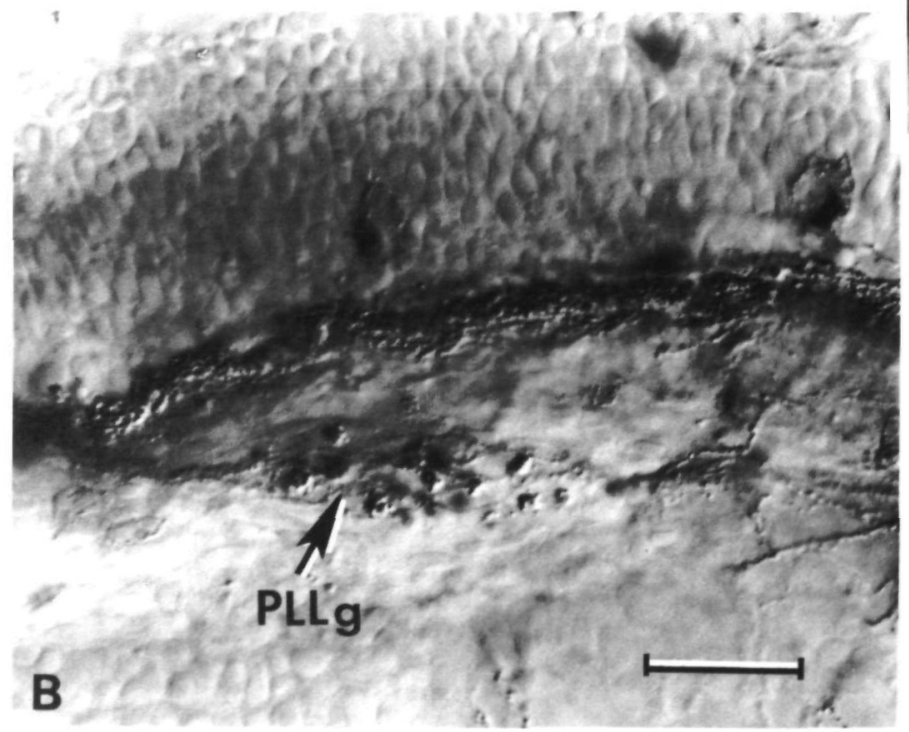

Fig. 11. The surfaces of primary motoneurons (panel $A$, PMn) and posterior lateral line ganglion cells (panel B, PLLG) are weakly labeled with $\mathrm{zn}-12$, although there is strong immunoreactivity in the juxtanuclear cytoplasm. In contrast, the ventral roots ( $v$, panel $A$ ) are well labeled, as are the peripheral fibers of the posterior lateral line ganglion (not shown). Sagittal view of $24 \mathrm{~h}$ zebrafish embryos in whole mount. The immunoreactive transverse myosepta are visible between the ventral roots, and Rohon-Beard cells are present above the motoneurons. Rostral is to the left. Bar $=25 \mu \mathrm{m}$.

reactivity is detected on the brain surface specifically where trigeminal sensory axons enter the brain, and later is concentrated in the basal lamina of the pathway along which the same axons grow (see also Metcalfe, 1989).

We observed labeling, in two instances, of both presynaptic neurons and their targets. Both the Mauthner cell and the growing trigeminal axons are immunoreactive, and we know that the Mauthner cell
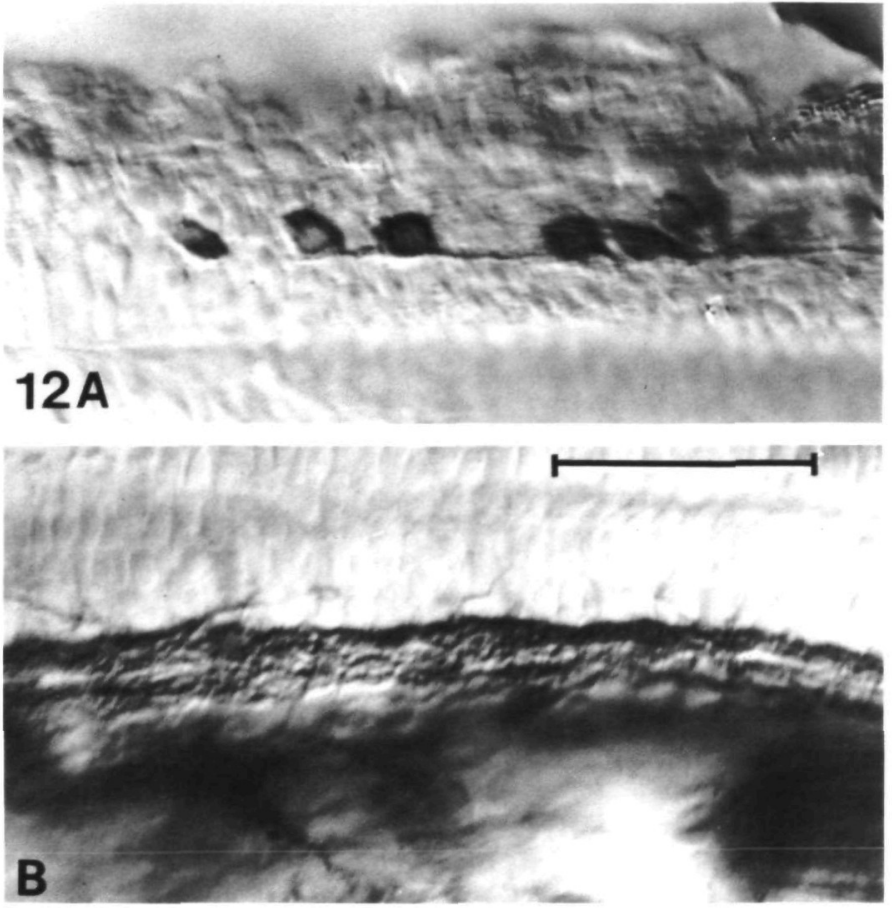

Fig. 12. Although ic cells are present early, they are not labeled with the $\mathrm{zn}-12$ antibody. These are horizontal views of the region of the hindbrain-spinal cord junction of $22 \mathrm{~h}$ zebrafish embryos. (A) This $25 \mu \mathrm{m}$ horizontal section was labeled with the monoclonal antibody $\mathrm{zn}-1$ (Trevarrow, 1990). The ic cells are prominent cells that overlie the medial longitudinal fascicle (mlf) and project axons caudally into the ipsilateral mlf. (B) View of the same region of an embryo labeled with $\mathrm{zn}-12$; no cells are labeled, although immunopositive axons of reticulospinal neurons are present in the mlf. Medial is to the bottom in (A) and to the top in (B). Rostral is to the left. Bar $=25 \mu \mathrm{m}$.

receives synaptic input from these axons (Kimmel $e t$ al. 1990 a). Similarly, primary motoneurons and their peripheral target cells, somitic muscle fibers, are both immunoreactive. Thus molecules that contain L2/ HNK-1 may function in synaptic target recognition or synapse formation, as proposed by Landmesser et al. (1988), who have shown that N-CAM and L1, glycoproteins that contain the L2/HNK-1 epitope, are each required for normal innervation of embryonic chick muscle.

In these cases of pathfinding and synaptic target interaction, the axonal growth cones as well as the surfaces they contact both express the L2/HNK-1 carbohydrate. Whereas we do not know what specific moelcule(s) carries the epitope, it is interesting that both N-CAM and L1, glycoproteins that do carry it, demonstrate homophilic binding (Rutishauser et al. 1988; Lemmon et al. 1989), which could therefore mediate the interactions we have described.

\section{Primary sensory neuronal development}

Rohon-Beard neurons and trigeminal ganglion neurons are the only neurons to express detectable levels of the L2/HNK-1 epitope in the embryo at $14 \mathrm{~h}$. These 
neurons, perhaps the first ones in the embryo to grow axons, are similar not only in their early development, but also in morphology and many other respects, although they occupy very different positions. They both mediate touch sensitivity (Roberts and Blight, 1975; Roberts and Hayes, 1977), their peripheral axons branch in a similar fashion in the skin, and develop from growth cones that have the same distinctive morphology. Their central axons independently locate the same central longitudinal fiber pathway and, growing in opposite directions towards the hindbrain at the same rapid rate, meet and appear to fasciculate upon one another.

These features are not generally shared among other primary neurons. For example, primary motoneurons in the trunk spinal cord are segmentally arranged and begin axogenesis at about 17-18 h (Myers et al. 1986), about an hour after the Rohon-Beard cells, located dorsally to them. Further, the motor axons grow very slowly (about $7 \mu \mathrm{m} \mathrm{h}^{-1}$ ) along segmentally restricted pathways. Rohon-Beard neurons are not segmentally distributed, and their peripheral sensory arbors grow rapidly to blanket multiple segments. Other primary sensory neurons also do not share features of the Rohon-Beard and trigeminal neurons: posterior lateral line sensory neurons grow axons at about $19 \mathrm{~h}$ (Metcalfe, 1985), and acoustico-vestibular neurons grow axons at $22 \mathrm{~h}$ (Kimmel et al. 1990a). Further, the central axons of these two classes of neurons grow much more slowly, and along different parallel pathways in the hindbrain (Metcalfe, 1989). Their peripheral growth cones are less elaborate and more club shaped, and the axons branch little, if at all. Although distinct from the tactile neurons (trigeminal and Rohon-Beard), these vibration-sensitive neurons (lateral line and acousticovestibular) develop similarly to one another. Sensory modality, then, appears to be correlated with particular patterns of development.

The similarities between the trigeminal and RohonBeard neurons suggest that, from before the time they initiate axons, they are following a common developmental program. This is particularly interesting considering that specification of cell identity is thought to be position-dependent in vertebrates, and that these two cell types occupy very different positions. One possibilty is that position is important, but at an earlier stage when their progenitors could be close, or closer, together. We know that they come from the same general region in the early gastrula (Kimmel et al. $1990 \mathrm{~b}$ ) and that neuronal precursors undergo extensive migrations during gastrulation, large-scale movements ceasing at 9-10 h (Kimmel and Warga, 1986), several hours before L2/HNK-1 expression is observed. Alternatively, these two cell populations might have been switched into the same developmental program without ever having been closely related by either position or cell lineage; examples are known in Caenorhabditis elegans (see Kenyon, 1985). These possibilities might be distinguished by examining the relationships of the progenitors of Rohon-Beard and trigeminal neurons in early embryos.
We thank Judith Eisen, Kohei Hatta and Monte Westerfield for their helpful discussions and comments on the manuscript; Mark Curry, Ruth Bremiller, Wendy Hodsdon, Tracy Bork, Reida Kimmel, and Harrison Howard for excellent technical assistance, and Kris Vogel for generously providing HNK-1 antibody. Supported by NIH grants NS17963, HD 22486 and the MDA.

\section{References}

Bronner-Fraser, M. (1987). Perturbation of cranial neural crest migration by the HNK-1 antibody. Devl Biol. 123, 321-331.

Chou, D. K. H., Ilyas, A. A., Evans, J. E., Costello, C, Quarles, R. H. AND Jungalwala, F. B. (1986). Structure of sulfated glucuronyl glycolipids in the nervous system reacting with HNK-1 antibody and some IgM seraproteins in neuropathy. J. biol. Chem. 261, 11717-11725.

Dodd, J. AND Jessell, T. M. (1988). Axon guidance and the patterning of neuronal projections in vertebrates. Sctence $\mathbf{2 4 2}$ 692-699.

Eisen, J. S., Myers, P. Z. ANd Westerfield, M. (1986). Pathway selection by growth cones of identified motoneurones in live zebra fish embryos. Nature 320, 269-271.

GirdeEstone, J. AND Weston, J. A. (1985). Identification of early neuronal subpopulations in avian neural crest cell cultures. Devl Biol. 109, 274-287.

Grunwald, D. J., Kimmel, C. B., Westerfield, M., Walker, C. AND STREISINGER, G. (1988). A neural degeneration mutation that spares primary neurons in the zebrafish. Devl Biol. 126, 115-128.

Hanneman, E., Trevarrow, B., Metcalfe, W. K., Kimmel, C. B. AND WeSTERFIELD, M. (1988). Segmental pattern of development of the hindbrain and spinal cord of the zebrafish embryo. Development 103, 49-58.

Hanneman, E. and Westerfield, M. (1989). Early expression of acetylcholinesterase activity in functionally distinct neurons of the zebrafish. J. comp. Neurol. 284, 350-361.

Harrelson, A. L. and Goodman, C. S. (1988). Growth cone guidance in insects: fasciclin $\amalg$ is a member of the immunoglobulin superfamily. Sclence 242, 700-708.

Herrick, C. J. ANd Coghill, G. E. (1915). The development of reflex mechanisms in Amblystoma. J. comp. Neurol. 25, 65-85.

Keilhauer, G., Faissner, A. and Schachner, M. (1985). Differential inhibition of neurone-neurone, neurone-astrocyte, and astrocyte-astrocyte adhesion by L1, L2, and N-CAM antibodies. Nature 316, 728-730.

Kenyon, C. (1985). Cell lineage and the control of Caenorhabditis elegans development. Phil. Trans. R. Soc. Lond. B 312, 21-38.

Kimmel, C. B., Hatta, K. and Metcalfe, W. K. (1990a). Early axonal contacts during development of an identified dendrite in the brain of the zebrafish. Neuron 4, 535-545.

Kimmel, C. B. AND WARGA, R. (1986). Tissue-specific cell lineages originate in the gastrula of the zebrafish. Science 231, 365-368.

Kimmel, C. B., WarGa, R. M. And Schilling, T. F. (1990b). Origin and organization of the zebrafish fate map. Development 108, 581-594.

Kimmel, C. B. ANd Westerfeld, M. (1990). Primary neurons of the zebrafish. In Signals and Sense (G. M. Edelman and M. W. Cowan, eds.) Wiley Interscience, New York. (in press).

Kruse, J., Keilhauer, G., Faissner, A., Timpl, R. and SCHACHNER, M. (1985). The J1 glycoprotein - a novel nervous system cell adhesion molecule of the L.2/HNK-1 family. Nature 316, 146-148.

Kruse, J., Mailhammer, R., Wernecke, H., Faissner, A., SOMmer, I., Goridis, C. ANd Schachner, M. (1984). Neural cell adhesion molecules and myelin-associated glycoprotein share a common carbohydrate moiety recognized by monoclonal antibodies L2 and HNK-1. Nature 311, 152-155.

Konemund, V., Jungalwala, F. B., Fischer, G., Chou, D. K. H., Keilhauer, G. and Schachner, M. (1988). The L2/HNK-1 carbohydrate of neural cell adhesion molecules is involved in cell interactions. J. Cell Biol. 106, 213-223. 
Kunst, E. and Campos-Ortega, J. A. (1989). The molecular genetics of early neurogenesis in Drosophila melanogaster. Bioassays 11, 95-100.

Kuwada, J. Y. (1986). Cell recognition by neuronal growth cones in a simple vertebrate embryo. Science $233,740-746$.

KuWADA, J. Y. (1987). Stereotyped pathfinding by identified growth cones in the embryonic spinal cord. Soc. Neurosci. Abs. 13, 1220.

Kuwada, J. Y., Bernhardt, R. B. And Chitnis, A. B. (1990). Pathfinding by identified growth cones in the spinal cord of zebrafish embryos. J. Neurosci. 10, 1299-1308.

Landmesser, L., Dahm, L., Schultz, K. and Rutishauser, U. (1988). Distinct roles for adhesion molecules during innervation of embryonic chick muscle. Devl Biol. 130, 645-670.

Lemmon, V., FarR, K. L. ANd Lagenaur, C. (1989). L1-mediated axon outgrowth occurs via a homophilic binding mechanism. Neuron 2, 1597-1603.

Matthew, W. D. and Patterson, P. H. (1983). The production of a monoclonal antibody that blocks the action of a neurite outgrowth-promoting factor. In Molecular Neurobiology: Cold Spring Harbor Symposium in Quantitative Biology 48, 625-632.

McGarry, R. C., Helfand, S. L., Quarles, R. H. and Roder, J. C. (1983). Recognition of myelin-associated glycoprotein by the monoclonal antibody HNK-1. Nature 306, 376-378.

Mendelson, B. (1986). Development of reticulospinal neurons of the zebrafish. II. Early axonal outgrowth and cell body position. J. comp. Neurol. 251, 172-184.

Mendelson, B. AND Kimmel, C. B. (1986). Identified vertebrate neurons that differ in axonal projection develop together. Devl Biol. 118, 309-313.

Metcalfe, W. K. (1985). Sensory neuron growth cones comigrate with posterior lateral line primordial cells in zebrafish. J. comp. Neurol. 238, 218-224.

Metcalfe, W. K. (1989). Organization and development of the zebrafish postenor lateral line. In The Mechanosensory Lateral Line: Neurobiology and Evolution (ed. S. Coombs, P. Gärner, and H. Münz), pp. 147-159. Springer-Verlag, New York.

Metcalfe, W. K., Kimmel, C. B. and Schabtach, E. (1985). Anatomy of the posterior lateral line system in young larvae of the zebrafish. J. comp. Neurol. 233, 377-389.

Metcalfe, W. K., Mendelson, B. and Kimmel, C. B. (1986). Segmental homologies among reticulospinal neurons in the hindbrain of the zebrafish larva. J. comp. Neurol. 251, 147-159.

Moos, M., TACKe, R., Scherer, H., TePlow, D., FrÜH, K. AND SCHACHNER, M. (1988). Neural adhesion molecule L1 as a member of the immunoglobulin superfamily with binding domains similar to fibronectin. Nature 334, 701-703.

Myers, P. Z., Eisen, J. S. AND Westerfield, M. (1986).
Development and axonal outgrowth of identified motoneurons in the zebrafish. J. Neurosci. 6, 2278-2289.

Ruopelle, R. J., MCGarRY, R. C. And Roder, J. C. (1986).

Adhesion properties of a neuronal epitope recognized by the monoclonal antibody HNK-1. Brain Res. 367, 20-25.

RoBerTs, A. AND Blight, R. (1975). Anatomy, physiology and behavioural role of sensory nerve endings in the cement gland of embryonic Xenopus. Proc. R. Soc. Lond. B 192, 111-127.

Roberts, A. ANd Hayes, B. P. (1977). The anatomy and function of 'free' nerve endings in an amphibian skin sensory system. Proc. R. Soc. Lond. B 196, 415-429.

Rutishauser, U., Acheson, A., Hall, A. K., Mann, D. M. and Sunshine, J. (1988). The neural cell adhesion molecules (NCAM) as a regulator of cell-cell interactions. Science $\mathbf{2 4 0}$, 53-57.

Rutishauser, U. and Jessell, T. M. (1988). Cell adhesion molecules in vertebrate neural development. Physiol. Rev. 68, 819-857.

Schabtach, E. and Parkening, T. A. (1974). A method for sequential high resolution light and electron microscopy of selected areas of the same material. J. Cell Biol. 61, 261-264.

Springer, T. A. (1987). Purification of proteins by precipitation. In Current Protocols in Molecular Biology (ed. F. M. Ausubel, R. Brent, R. E. Kingston, D. D. Moore, J. G. Seidman, J. A. Smith, and K. Struhl), John Wiley and Sons, Inc., New York.

Trevarrow, B., Marks, D. L. and Kimmel, C. B. (1990). Organization of hindbrain segments in the zebrafish embryo. Neuron 4, (in press).

Tucker, G. C., Aoyama, H., Lipinski, M., Tursz, T. and Thiery, J. P. (1984). Identical reactivity of monoclonal antibodies HNK-1 and $\mathrm{NC}-1$ : conservation in vertebrates on cells derived from the neural primordium and on some leucocytes. Cell Differentiation $14,223-230$.

Vincent, M., Duband, J. L. and Thiery, J. P. (1983). A cell surface determinant expressed early on migrating avian neural crest cells. Develop. Brain Res. 9, 235-238.

VinCENT, M. AND ThieRY, J. P. (1984). A cell surface marker for neural crest and placodal cells: further evolution in peripheral and central nervous system. Devl Biol. 103, 468-481.

Westerfield, M., McMurray, J. and Eisen, J. (1986). Identified motoneurons and their innervation of axial muscles in the zebrafish. J. Neurosci. 6, 2267-2277.

Wilson, S. W., Ross, L. S., Parrett, T. AND Easter, S. S. JR. $(1990)$. The development of a simple scaffold of axon tracts in the brain of the embryonic zebrafish, Brachydanio rerio. Development 108, 121-145. 